\title{
Sensitivity analysis using simulations for a ground source heat pump - implementation on a solar passive house
}

\author{
Gheorghe Ilisei ${ }^{1,2}$, Tiberiu Catalina ${ }^{1,2}$ and Robert Gavriliuc ${ }^{1,2}$ \\ ${ }^{1}$ Technical University of Civil Engineering, Faculty of Building Services, Bucharest, Romania \\ ${ }^{2}$ Romanian Geoexchange Society, Bucharest, Romania
}

\begin{abstract}
Having in sight the need for a strong reduction in $\mathrm{CO} 2$ emissions and the fluctuation of the price of fossil fuels, the ground source resources alongside with the ground source heat pumps are becoming more and more widespread for meeting the heating/cooling demand of several types of buildings. This article targets to develop the thermal modelling of borehole heat storage systems. Trying to emphasize some certain advantages of a GSHP (ground source heat pump) with vertical boreholes, a case study analysing a residential solar passive house is presented. The numerical results are produced using different modelling software like DesignBuilder, EED (Earth Energy Designer) and a sizing method for the length of the boreholes (ASHRAE method). The idea of sizing the length of boreholes (main design parameter and good index in estimating the system's cost) using two different methods shows the reliability of this modelling tool. The study shows that borehole's length of a GSHP system can trigger a difference in electricity consumption up to $22 \%$. Moreover, this sensitivity analysis aims to prove that the design of the whole system can be done beforehand just using modeling tools, without performing tests in-situ.
\end{abstract}

\section{Introduction}

In the context of Paris agreement where the international community agreed that the average global temperature must not rise more than $2^{\circ} \mathrm{C}$ above the pre-industrial temperature in order to mitigate the effect of global warming and climate change, some strong climate actions need to be implemented and renewable energies (alongside geothermal resources) must enlarge their use and applications.

Energy use in buildings represents a major share of the overall energy used in developed countries. The reduction of the energy demand and the efficient energy use are often seen as feasible ways for a more sustainable energy use in the built environment.

Being part of geothermal renewable energy, ground source heat pumps (GSHPs) are efficient systems to supply heating and cooling energy to buildings, but their design is critical for their performance. However, their performance depends on the cooling and heating demand and on the environmental conditions (geometric and physical properties of its components and the thermo-hydrogeological properties of the surrounding soil) [1], [2].

This type of equipment (ground source heat pump on vertical borehole heat exchangers) is not used at a large scale in the whole world. There are many countries, some even in Europe, where these types of equipment are often not considered in the design of a building due to lack of studies, information, available examples and insufficient cost analyses. [3]

The purpose of this study is to make a link between two simulation programs and another tool for sizing the length of geothermal loop (ASHRAE method) and to combine the data provided from them to have the best analysis of a GSHP implementation and analysis.

\begin{tabular}{|c|c|}
\hline \multicolumn{2}{|c|}{ Nomenclature } \\
\hline GSHP & Ground Source Heat Pump \\
\hline HDPE & High Density Polyethylene \\
\hline EED & Earth Energy Designer \\
\hline BHE & Borehole Heat Exchanger \\
\hline ASHRAE & $\begin{array}{l}\text { The American Society of Heating, } \\
\text { Refrigerating and Air Conditioning }\end{array}$ \\
\hline HVAC & Heat Ventilation and Air Conditioning \\
\hline GSHE & Ground Source Heat Exchanger \\
\hline $\mathbf{k}_{\mathbf{p}}$ & Thermal conductivity of the HDPE pipes \\
\hline d & Drilling diameter \\
\hline $\mathbf{k g}$ & $\begin{array}{l}\text { Thermal conductivity of the well's } \\
\text { filling material (grout) }\end{array}$ \\
\hline $\mathbf{k}_{\text {s }}$ & Thermal conductivity of the ground/soil \\
\hline $\mathbf{T}_{\mathrm{g}}$ & Initial temperature of the ground \\
\hline $\mathbf{T}_{\mathbf{p}}$ & $\begin{array}{l}\text { Correction temperature linked to the } \\
\text { interaction with the other } \\
\text { wells/boreholes }\end{array}$ \\
\hline $\mathbf{R}_{\mathbf{b}}$ & $\begin{array}{l}\text { Thermal resistance of the } \\
\text { wells/boreholes }\end{array}$ \\
\hline
\end{tabular}

* Corresponding author: ilisei.g@gmail.com 
To convince a beneficiary to adopt a geothermal heat pump for a residential house it is mandatory, besides presenting the system's advantages, that the system will be financially competitive with other HVAC options. Thus, it is essential that the system is not oversized, so it can be considered a viable solution.

In this context, this article aims to contribute to the development of thermal modeling of closed loop geothermal heat pump systems. These systems are widely implemented in some cold climates (countries from Northern Europe, United States, Canada), but the fact that these systems are also efficient for cooling residential buildings should trigger a larger utilization in warmer countries too. Additionally, the research looks to increase the interest of such systems using renewable energies in areas where these systems are not applied for residential buildings by highlighting the advantages which will be obtained when implementing a ground source heat pump even for a building with small dimensions, especially in zones where the implementation of this systems is not wide-spread (e.g. Central and Eastern Europe). To develop the implementation of a relatively new system, such as ground source heat pumps in the areas mentioned above, it is necessary to prove its advantages over existing systems.

A ground heat storage consists of an array of vertical boreholes placed in such a way that promotes the mutual thermal interaction between the ground heat exchangers, creating the necessary conditions required to effectively store and retrieve heat. [4]

The principle of vertical borehole heat exchangers is based on the fact that below a depth of about 10 meters (depending on the geographical location and geology), the soil temperature is constant throughout the year [5]. Thus, one can have stable performances throughout the operating season.

Considering that the performances of these exchangers are not directly related to the external climatic conditions (unlike horizontal heat exchangers), the mobilized surface area is very small and can even be considered as zero since they can be installed under car parks or buildings, provided that their HDPE pipes are not subjected to excessive mechanical stresses.

The performance of a closed loop GSHP depends on many variables like the thermal conductivity of the grout, of the soil, of the pipe material, the heat carrier fluid, the number of pipes, et cetera.

Thus, most of these parameters influencing the COP of the system and the feasibility of such a system are related to the ground properties. [6]

A thermal response test provides the thermal conductivity of the soil $\lambda$ and the thermal resistance of the well $\mathrm{Rb}$. This test consists in injecting or extracting a constant flow of energy per unit of length [m]. The test can determine the soil response by measuring the temperature difference $\Delta \mathrm{T}$ [7]. A thermal response test can be an expensive test to be performed before projecting a residential building like the one analyzed in this study.
Thermal response test unit

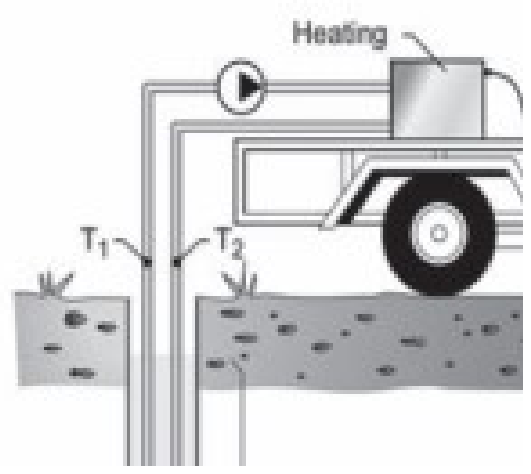

Fig. 1. Conceptual picture of a thermal response test [15]

In this case, numerical simulation and modeling tools can be used to provide the data needed for projecting a GSHP system. Numerical modeling can be used in order to determine beforehand the length of the boreholes using in the main time the properties of the exchanger and the thermo-hydrogeological parameters of the soil and also the peak demand and the monthly consumption of the building, data taken from the modeling tools DesignBuilder and EED.

\section{Methodology}

The sensitivity analysis has been performed on the design parameters of the BHE (number and length of pipes, material properties) and on the physical properties of the soil (thermal conductivity of ground, grout, the type of brine) in order to evaluate their impact on the performance of the GSHP.

Thus, for developing the modeling of a closed loop geothermal heat pump system, the paper presents a procedure for determining the properties mentioned above.

Taking into consideration that many implemented ground source heat pump systems for residential houses do not work at full capacity, this procedure, using several modeling tools, aims at a correct dimensioning by combining the results of the programs and adapting the BHE length according to the geotechnical parameters of the earth. This is essential in optimizing the system.

The case study was carried out on an energyefficient house EFdeN House, an active single-family dwelling that was planned and built in Bucharest for academic purposes. [3] The EFdeN house is an active house that produces more energy than it consumes (positive annual report) and reaches the indoor comfort parameters corresponding to a green, comfortable building.

The house has been designed to meet European norms and standards regarding the energy efficiency. The house, designed in Bucharest as a very efficient solar house, participated at the contest Solar Decathlon Europe [8] and it is a prototype that doesn't have any boundaries regarding the location where this house can be implemented. 


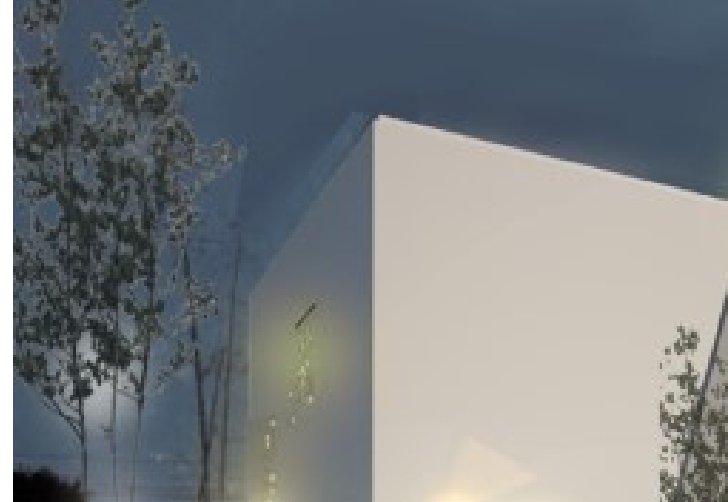

Fig. 2. Solar House EFdeN - outside photo [8]

Important building data [8]:

- Height regime: ground floor + first floor

- Building destination: residential building

- Built area: $170 \mathrm{~m}^{2}$

- Floor height: $2.5 \mathrm{~m}$

- Number of occupants: 3

- Location: Bucharest, Romania.

- Cooling load (summer): 3.5 [kW] (data taken from DesignBuilder simulation)

- Heating load (winter): 4.2 [kW] (data taken from DesignBuilder simulation)

Various simulations were carried out on the house EFdeN by using various tools of advanced modelling, where Design Builder and EED (Earth Energy Designer) are two of them. The simulations are based on different types of pumps, different types of soils and different types of vertical forage. Therefore, even though the analyzed main building is the EFdeN house, different geotechnical parameters for different zones were taken into consideration with the purpose of assessing the feasibility of a ground source heat pump in areas where the systems lack popularity, compared to Northern Europe for instance.

Finally, the study will present the relation between the results obtained in the framework of the simulations made with the DesignBuilder software, the simulations made with the EED (Earth Energy Designer) software, and the sizing results of the wells / boreholes using the Excel program. The hypothesis is that if the obtained relations are reliable and durable, they represent a viable option to be used for geothermal system design with GSHP.

In order to show the possibility of implementing a geothermal heat pump with vertical drilling (a closed loop system) for a residential building, some simulations are proposed to solve all the unknowns.

\subsection{Design Builder}

DesignBuilder is an EnergyPlus-based software tool used for the measurement and control of energy, carbon, lighting and comfort [9], [10].

First, in order to meet the heating / cooling demand of the building, the architecture of the house is introduced in the DesignBuilder software. This is followed by defining all the scenarios of the occupations, the Heating Ventilation and Air Conditioning (HVAC) system (see picture 4), lighting, et cetera to give the software to return the correct needs in heating and air conditioning.

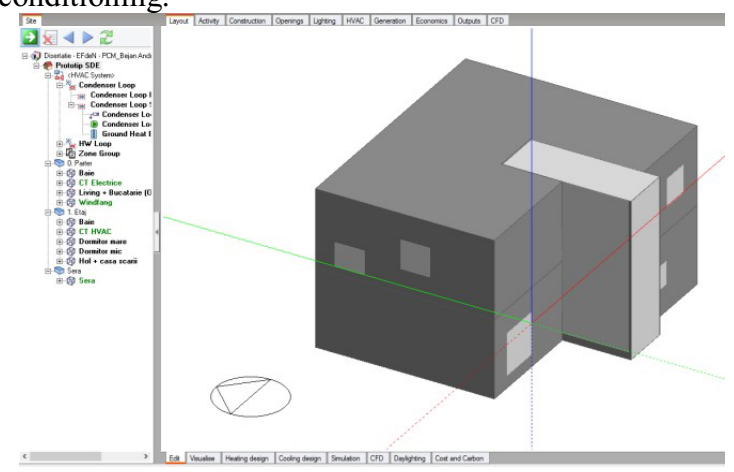

Fig. 3. Solar House EFdeN - 3D Model in Design Builder

The HVAC system contains a geothermal heat pump with vertical BHE (Borehole Heat Exchanger) which aims at providing heating and cooling demand to the building but not the supply of domestic hot water. With regard to the HVAC system which was introduced in the context of simulations in Design Builder, some input data are needed; the type and power of heat pump, the vertical borehole length, the number of pipes, of vertical GSHE and other data concerning the thermal conductivity of the soil, grout, pipe, filling material, et cetera.

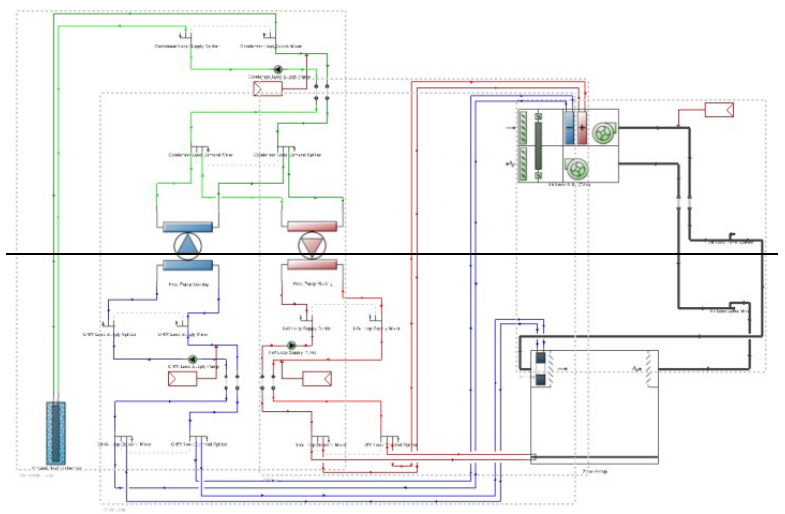

Fig. 4. Design Builder - the architecture of HVAC system

The sizing of the network of vertical wells is needed to introduce all these data. Two methods are available: either using the EED (Earth Energy Design) software to size the system (the length of the wells), or a spreadsheet in Excel built by researchers using the ASHRAE method. To ensure that the obtained results are reliable, it was decided to use both methods to facilitate the verification of the dimensioned system. This approach shows how the simulations are connected between them to obtain a good sizing of the system and additionally, a good energy efficiency of it, by highlighting the necessity of using different modeling tools.

During the DesignBuilder simulation three types of GSHP were analyzed to deduce in what measure the 
selection of the pump is important as well. In the table 1, the types of GSHP utilized can be found.

Table 1: Types of GSHP utilised in DesignBuilder software

\begin{tabular}{|c|c|c|c|c|}
\hline No. & Name & \multicolumn{2}{|c|}{ Performance } & Unit \\
& & \multicolumn{2}{|l|}{} \\
\hline GSHP I & Carrier 36 & Pt & 12500 & $\mathrm{~W}$ \\
\cline { 3 - 5 } & $\mathrm{DB}$ & $\mathrm{Pabs}$ & 2600 & $\mathrm{~W}$ \\
\cline { 3 - 5 } & & $\mathrm{q}$ & 0.57 & $\mathrm{~L} / \mathrm{S}$ \\
\hline GSHP II & PAC & $\mathrm{Pt}$ & 6500 & $\mathrm{~W}$ \\
\cline { 3 - 5 } & Clint & $\mathrm{Pabs}$ & 1600 & $\mathrm{~W}$ \\
\cline { 3 - 5 } & CWW18 & $\mathrm{q}$ & 0.24 & $\mathrm{~L} / \mathrm{S}$ \\
\hline GSHPIII & Tonon & $\mathrm{Pt}$ & 4800 & $\mathrm{~W}$ \\
\cline { 3 - 5 } & Forty & $\mathrm{Pabs}$ & 1500 & $\mathrm{~W}$ \\
\cline { 3 - 5 } & & $\mathrm{q}$ & 0.23 & $\mathrm{~L} / \mathrm{S}$ \\
\hline
\end{tabular}

\subsection{ASHRAE method}

The dimensioning of the vertical BHE was done with the ASHRAE method by modeling the thermal heat exchange between soil and heat transfer fluid of vertical buried heat exchangers. This method can be used when there are known more precisely the properties of the soil. In our case, the simulations in EED provided this data.

The heat exchange between a well and the soil has been defined, taking place between the brine circulating in the U-tubes (2 U-tubes per well) at a temperature $T_{f}$ and the soil zone [11]. The soil zone is disturbed by the presence of the well having the temperature $T_{s}$ equal to the initial soil temperature before the onset of geothermal site operation (see Figure 5). It will be assumed that the heat transfer between the surface of the well at the temperature $T_{p}$ and the fluid at the temperature $T_{\mathrm{f}}$ is in a steady sliding state, taking into account that its dynamic is much faster than the heat transfer between the ground and the GSHE surface.

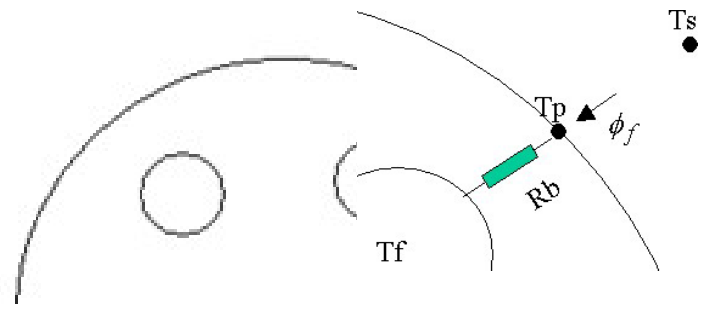

Fig. 5. Electrical analogy between HDPE pipe and soil

It was made the calculation of $\mathrm{T}_{\mathrm{p}}$ and $\mathrm{L}$, where $\mathrm{L}$ is total length of the BHE, assuming a variable groundbased thermal flow as a function of time, and not at a constant ground thermal flow.

\subsection{Earth Energy Designer}

Earth Energy Designer (EED) is a software for the design of vertical boreholes serving as a heat exchanger for a heat pump [12]. To simulate the building with the EED software, the heating and cooling demands for a year are required, as well as the heating / cooling peak load (or the total losses of the building for heating / cooling the building). All the necessary data was provided as a result of the building simulation with DesignBuilder.
The ground properties, the borehole exchanger properties and the heat carrier fluid properties were introduced in order to obtain the total length of the borehole needed to confront the building thermal losses.

Table 2. Soil and GSHP brine properties

\begin{tabular}{|c|c|}
\hline \multicolumn{2}{|c|}{ Soil properties } \\
\hline Characteristics & Value \\
\hline Thermal conductivity & $2.2 \mathrm{~W} / \mathrm{mK}$ \\
\hline Volumetric heat capacity & $2.4 \mathrm{MJ} / \mathrm{m}^{3} \mathrm{~K}$ \\
\hline Ground surface temperature & $10.60^{\circ} \mathrm{C}$ \\
\hline Thermal conductivity of the grout & $1.8 \mathrm{~W} / \mathrm{m}^{2}$ \\
\hline \multicolumn{2}{|c|}{ Brine properties } \\
\hline Thermal conductivity & $0.372 \mathrm{~W} / \mathrm{mK}$ \\
\hline Specific heat capacity & $4030 \mathrm{~J} / \mathrm{kgK}$ \\
\hline Density & $961 \mathrm{~kg} / \mathrm{m}^{3}$ \\
\hline Freezing point & $-25^{\circ} \mathrm{C}$ \\
\hline
\end{tabular}

EED has data bases that provide the soil parameters (thermal conductivity and specific heat - see Table 2), as well as the properties of piping materials and heat transfer fluids. The average monthly heating and cooling loads of the analyzed building, obtained with DesignBuilder, are the input data in EED.

When sizing the length of the borehole, the same values from table 2 were taken into consideration for both EED and ASHRAE method.

\section{Results}

A comparison between the results of the simulations has been made, with the aim to assess the relative influence of each parameter on the performance of the GSHP or on the length of the borehole. The results of the long-term BHE simulations have been processed and compared in order to understand which is the relative importance of each parameter (between the thermal conductivity of the ground, of the grout, of the pipe, the mean temperature of the ground, et cetera) on the performances of the system (COP and consumption of electricity by the compressor of the GSHP) and on the total length of the borehole. The length of the Borehole Heat Exchanger plays a crucial role in the design process, because it is responsible for almost half of the total installation cost of the GSHP [13], [14].

It is important to mention that the electricity consumption which is calculated during this study takes into consideration only the electricity consumed by the GSHP, leaving aside the electricity consumed by other equipment placed on the circuit of a ground source heat exchanger (for instance the circulation pumps).

Following a simulation/calculation with all the tools mentioned in the methodology, assessing all the input needed for the system (peak loads, heating/cooling consumptions, total length of the borehole), a reference case was analysed using the soil properties from the table 2, one specific GSHP, a specific type of brine, a defined number of pipes in the borehole and a determined length of the BHE (see table 4). 
Starting from this reference case, a lot of simulations were done afterwards in order to identify how the change of one parameter (e.g. thermal conductivity of the grout), can influence other parameters (e.g. COP of the pump, the length of the BHE) and vice versa.

During the simulations, 3 types of GSHP were analysed (with the following heating capacities: 12.5 $\mathrm{kW}, 6.5 \mathrm{~kW}$ and $4.8 \mathrm{~kW}$ ), two design of BHE (single U and double $U$ ) and several locations, to vary the mean temperature of the soil, several types of ground, grout and brine.

When analysing the result, the first satisfactory result was represented by the fact that the total length of the borehole obtained with the ASHRAE method for the solar building was $39 \mathrm{~m}$, while with the modelling tool EED it was obtained a total length of $40 \mathrm{~m}$. These results show the reliability of the sizing method for the total length of the BHE (double U). The total length of the BHE for the analysed building has a low value due to the good envelope of the building which decreased the total losses of the building for heating. Also, in the reference case, some ideal values for thermal conductivity of ground and grout, parameters which can influence a lot the total length of BHE as it will be seen in the following results. After assessing the length of the borehole heat exchanger (BHE) needed for the heating and cooling of Efden building, the next step was to start to vary the types of soil, filling material, GSHP, location and others in order to see which factors have the higher influence.

The main parameters analysed are the thermal conductivity of the well filling material (the grout) $(\mathrm{kg})$, the thermal conductivity of the ground (ks) and the initial temperature of the ground $(\mathrm{Tg})$.

First, with the ASHRAE method, most of the parameters were analysed in order to see how they can influence the total length of the BHE. This is very important for the feasibility of such a system as the BHE's length is essential in order to assure that the system is not oversized so it can be considered a viable solution. Nonetheless, not all of them have a higher influence and thus some of them will not be presented here.

The greatest influence on the length of the BHE is given by $\mathrm{k}_{\mathrm{g}}$. Hence, if the thermal conductivities of the soil and the filling material and the initial soil temperature are all underestimated by $10 \%$ each, the error on the BHE length can hit a value of approximately $30 \%$ [3].

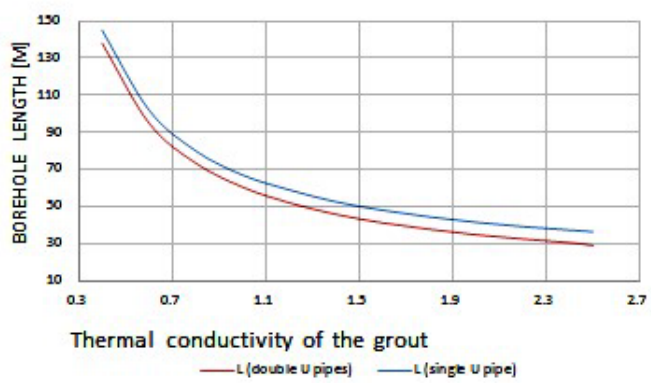

Fig. 6. Influence of the thermal conductivity of the filling material on the BHE length.

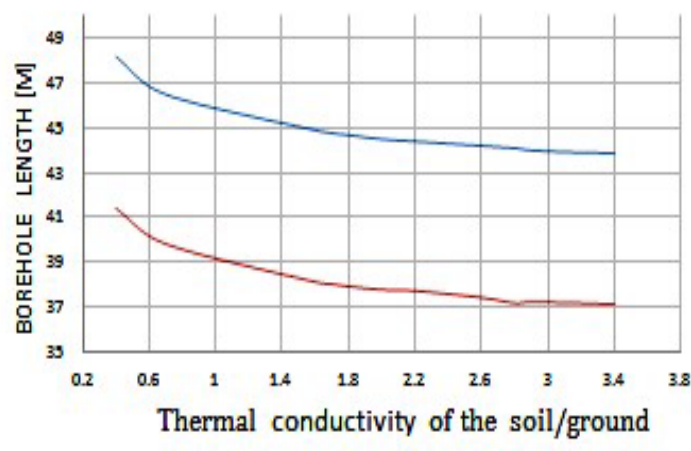

- L( doubre U pipes) - L(singte U pipe)

Fig. 7. Influence of the thermal conductivity of the soil on the BHE length

It is important to mention that this method of sizing the length of the BHE can be used only when the thermal conductivities of the soil and of the filling material are known precisely. Thus, the use of the EED (Earth Energy Designer) software which has a good database of the different types of soil and their properties, made it possible to obtain results without the need of performing a thermal response test beforehand.

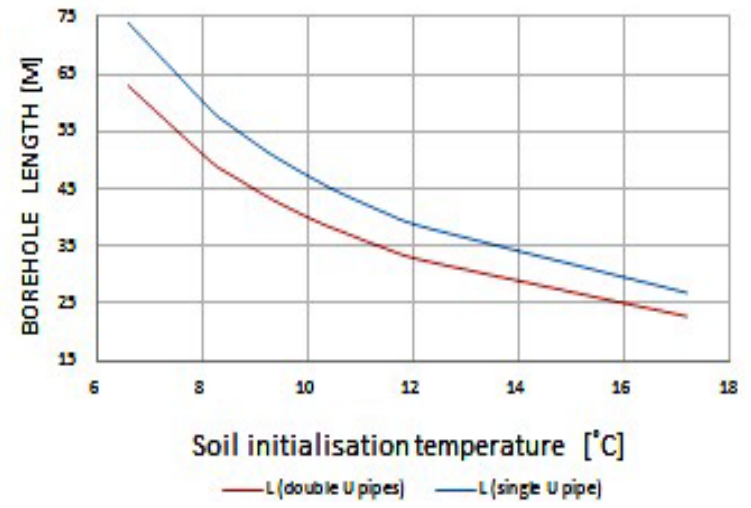

Fig. 8. Influence of the mean ground temperature on the BHE length

The thermal conductivity of the soil, along with the mean temperature of the implemented project ground have also a big influence on the BHE length, as can be seen in figures 7 and 8 . However, the gap is not as high as in the figure 6 . To further see the way the thermal conductivity of the grout is influencing the length of the $\mathrm{BHE}$, table 3 can be analysed. Table 3 is presenting the relation between these 2 parameters after simulations carried out only with the software EED.

Table 3: The relation between the length of the borehole and the thermal conductivity of the grout

\begin{tabular}{|c|c|}
\hline $\mathbf{k g}(\mathbf{W} / \mathbf{K m})$ & Length of borehole (m) \\
\hline 0.8 & 51 \\
\hline 1.4 & 46 \\
\hline 1.6 & 45 \\
\hline
\end{tabular}




\begin{tabular}{|c|c|}
\hline 1.8 & 44 \\
\hline 2 & 43 \\
\hline 2.2 & 43 \\
\hline
\end{tabular}

It can be observed that the discrepancy is not as big as in figure 6 , because to obtain a difference of $30 \%$ in the borehole's length the difference of the conductibility of filling material must be higher. Nonetheless, the effect of the filling material is still important when dimensioning the length of the BHE.

Additionally, from other point of view, the difference shown in figure 6 is very high and even though this parameter $(\mathrm{kg})$ has indeed a strong influence on the system, it may not be so obvious. For instance, when analysing the simulation carried out with Design Builder, these parameters influence the electricity consumption of GSHP, but not in such a radical manner.

Regarding the connection between the results from Design builder \& EED/ method ASHRAE, the purpose was to show how the ground parameters can influence the electricity consumption and thus the COP of the GSHP when maintaining the same length of the BHE and the same GSHP.

Table 4. Conductivity values for soil, filling material, pipes and simulation results for 3 cases (reference case and another two cases with improved/weakened conductivity

\begin{tabular}{|c|c|c|c|}
\hline \multicolumn{4}{|c|}{ values) } \\
\hline $\begin{array}{c}\text { Conductivity } \\
\text { (W/mK) }\end{array}$ & $\begin{array}{c}\text { Lower } \\
\text { conductivity } \\
\text { values }\end{array}$ & $\begin{array}{c}\text { Reference } \\
\text { case }\end{array}$ & $\begin{array}{c}\text { Very high } \\
\text { conductivi } \\
\text { ty values }\end{array}$ \\
\hline U type pipes & 0.39 & 0.42 & 0.42 \\
\hline Filling material & 0.7 & 1.8 & 2.5 \\
\hline Soil & 0.7 & 2.2 & 2.6 \\
\hline \multicolumn{4}{|c|}{ Results - annual values } \\
\hline $\begin{array}{l}\text { Heating energy } \\
(\mathrm{kWh})\end{array}$ & 2611 & 2611 & 2611 \\
\hline $\begin{array}{c}\text { Electricity } \\
\text { consumption } \\
(\mathrm{kWh})\end{array}$ & 773.9 & 679.5 & 666.8 \\
\hline $\begin{array}{l}\text { Coefficient of } \\
\text { Performance (-) }\end{array}$ & 3.37 & 3.84 & 3.91 \\
\hline
\end{tabular}

Hence, after a short analysis of the table it can be observed that the consumption for heating the building is smaller if the conductivities for soil and filling material have higher values. To be more explicit, it can be stated that electricity consumption drops by approximately $12 \%$ for the reference case and by almost $14 \%$ for the system with almost ideal conductivity values (compared to first case - with lower conductivity values).

Moreover, this table highlights the connection between the COP of the pump and the thermal conductivity of the soil and of the filling material.

Finally, the purpose was to connect the most two important parameters when designing a GSHP served by BHE: COP of the pump and the length of the BHE. Additionally, a connection between the electricity consumption of the compressor and the length of the borehole was made (which can be seen in figure 9)

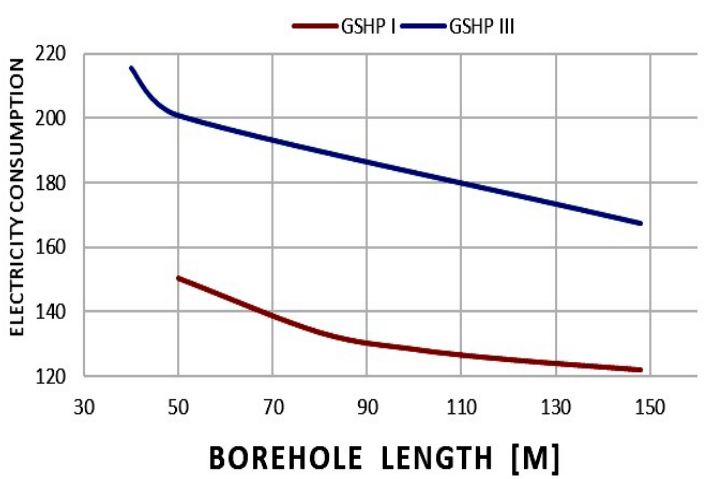

Fig. 9. Change in the electricity consumption at different borehole lengths (numbers for GSHP I and GSHP III are taken from table 1)

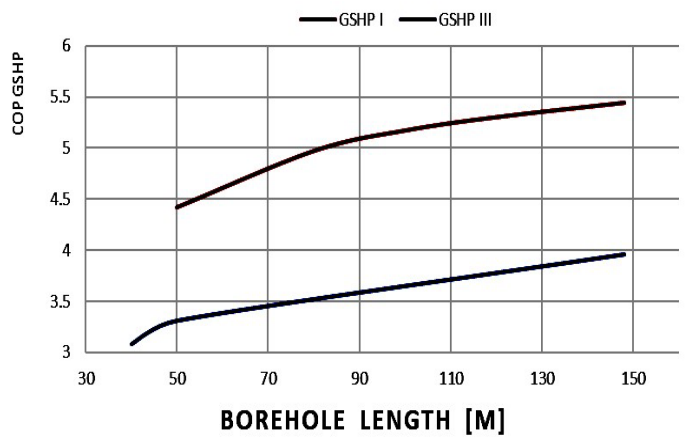

Fig. 10. Change of COP at different borehole lengths

Analysing the graphs presented above, it can be observed in what manner the length of the BHE affects the COP of the pumps and thus the electricity consumption. The differences are important. For the same heat pump (taking for example GSHP III - from table 1) the difference in electricity consumption is $22 \%$. However, the difference/gap chosen in well length is really important (the length of the borehole was tripled during this graphic).

It can be concluded that tripling the length of the boreholes from $50 \mathrm{~m}$ to $150 \mathrm{~m}$ decreased the energy consumption from $150 \mathrm{kWh}$ to $120 \mathrm{kWh}(-20 \%)$ for GSHP type I and from $210 \mathrm{kWh}$ to $165 \mathrm{kWh}(-22 \%)$ for GSHP type III.

\section{Discussion and Conclusion}

The purpose of this study was to supply a modeling tool by making correlations between two different modeling programs and another tool for sizing the length of geothermal loop (ASHRAE method) and combining the data provided from them in order to obtain a tool that would be used for easy modeling of a system that contains a geothermal heat pump served by vertical geothermal BHE (borehole heat exchanger). Both software instruments and the ASHRAE method give important information for the design of vertical buried heat exchangers. 
The first software used, Design Builder, was useful in the first phases both in simulating the house in order to assess the energy demand for heating/cooling and for simulating the HVAC system (GSHP on vertical borehole exchanger. The software provided the following information:

- the influence of the length of boreholes on the coefficient of performance;

- the influence of the thermal conductivity of filling material, soil and pipe on the electricity consumption of the heat pump;

Besides Design Builder, the software EED (Earth Eneergy Designer) displayed how heating requirements and maximum loads influence the boreholes length and how the conductivity of soil, filler material and soil temperature influence the boreholes sizing.

The sizing method (ASHRAE) gave the necessary BHE length to meet the maximum loads of the EFdeN house, the analysed building in this paper, and it was used to highlight the reliability of the results. In order to ensure that the results obtained are reliable, it was decided to use both methods (EED and ASHRAE method) to facilitate the verification of the dimensioned system.

To conclude, considering that some software may have limitations (e.g. Design Builder does not directly indicate the direct influence of changing the soil type or heat pump on the lengths of drilling (but on electricity consumption), it is advisable to combine the results of simulations with several programs.

Even though the study analyses only one building, a solar efficient residential house, the steps used in this paper are the same for any building. Hence, this can be used as an important and efficient tool for sizing a GSHP served by BHE systems, even in the earliest stages of the implementation of such a project. This assessment is of great importance, taking into consideration the fact that the length of the Borehole Heat Exchanger is responsible for almost half of the total installation cost of the GSHP.

In this way, with a correct design of the BHE length, the cost of the system will decrease, and these kinds of systems could become more competitive when choosing a HVAC for residential heating, even in countries where the systems are not yet developed due to the initial cost of the system (like Central and Eastern Europe).

\section{Further work}

Taking into account the fact that many countries from Central and Eastern Europe are facing a lack of implementation of this kind of systems (geothermal heat pumps on vertical borehole heat exchangers) to heat/cool buildings with small dimensions (in comparison with Sweden, France, et cetera.), an analysis of the implementation costs of such a system is also necessary in order to show the feasibility of a geothermal heat pump.

An economic study showing the implementation cost of the system in the analyzed building could highlight in a better way the advantages which can be obtained with the system.

It would also be interesting if the simulations in DesignBuilder took buildings from different areas into calculation, in order to see how the ground temperature influences the electricity consumption.

Concerning the dimensioning of the GSHP and the length of the pipes, other software could also be used:

- GLD (Ground Loop Designer) represents a great alternative and it is the choice of the professionals in more than 62 countries. GLD is the main software suite for the design of geothermal heat pump systems and in-ground heat exchanger.

-EWS (Erd-Waerme-Sonden), a software developed in Switzerland.

\subsection{Acknowledgement:}

The paper has been elaborated within the research activities of the European Project "Most easy, efficient and low cost geothermal systems for retrofitting civil and historical buildings", acronym GEO4CIVHIC - grant agreement No. 792355, covering Task 5.4-Modelling of virtual cases study, Sub task 5.4.4 Virtual case No. 4: Residential building in Bucharest (ROMANIA).

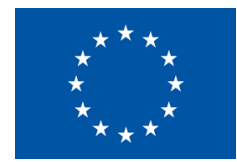

\section{References}

1. Marco Molinari, Alberto Lazzarotto, Folke Bjork "The application of the parametric analysis for improved energy design of a ground source heat pump for residential buildings", Elsevier magazine, Vol. 63, 2013

2. Alessandro Casasso, Rajandrea Sethi*, Sensitivity analysis on the performance of a ground source heat pump equipped with a double U-pipe borehole heat exchanger, Torino, Italy, 2014

3. Ilisei G., Catalina T., Gavriliuc R. Alexandru M. Implementation of a geothermal heat pump system in a passive house, 1st Conference of UTCB Doctoral School, Bucharest, Romania, 2018.

4. Alberto Lazzarotto "Developments in Ground Heat Storage Modeling", Thèse du doctorat, Stockholm, 2015

5. B. Sanner, Some history of shallow geothermal energy use, International summer school on Direct Application of Geothermal Energy, 2001, 10 p

6. Delaleux F, Py X, Olives R, Dominguez A, Enhancement of geothermal borehole heat exchangers performances by improvement of bentonite grouts conductivity, Applied Thermal Engineering, 33-34 (2012) 92-99

7. ADEME ( Agence de l'environment et de la maitrise de l'Energie), etude de faisabilite mise en place de pompe(S) a chaleur geothermique(s) sur 
aquifere superficiel ou sur champ de sondes, France, 2014

8. Andrei Bejan, Tiberiu Catalina, The implementation of phase-change materials in efficient residential houses, Bucharest, 2015

9. http://www.altensis.com/en/services/designbuildersoftware/

10. http://www.designbuilder.co.uk/helpv3.4/\#GSHPCa seStudy.htm

11. Valentin Trillat, Intégration énergétique dans les bâtiments par l'utilisation combinée de l'énergie solaire et de la géothermie basse température, Universite de Savoie-Chambery, France, 2006

12. https://buildingphysics.com/eed-2

13. Michopoulos A, Kyriakis N, The influence of a vertical ground heat exchanger length on the electricity consumption of the heat pumps, Renewable Energy, 35 (2010) 1403-1407.

14. Blum P, Campillo G, Kölbel T. Techno-economic and spatial analysis of vertical ground source heat pump systems in Germany. Energy 2011.

15. Gehlin, S. - Thermal response test. Method development and evaluation. $\mathrm{PhD}$ Thesis, Sweden 2002. 